\title{
LA ECONOMÍA POLÍTICA DE LA REFORMA TRIBUTARIA PROGRESIVA EN CHILE
}

Tasha Fairfield"

n 2009 el 1\% de los adultos de ingreso más alto en Chile obtu-
vo el $22 \%$ del ingreso nacional ${ }^{1}$. Pero el impuesto de renta que ellos pagaron fue menor: una tasa efectiva promedio de menos del $16 \%$, frente al $24 \%$ en Estados Unidos ${ }^{2}$. La reforma tributaria de alto perfil de la presidente Michelle Bachelet de 2014 intentó cambiar esta situación. Durante la campaña de 2013, ella anunció planes para incrementarlo en un 3\% del PIB gravando a las élites económicas del país para financiar la reforma de la educación pública. Este proyecto tributario, que envió al Congreso poco después de su posesión, fue una drástica ruptura con la experiencia de reformas menores y usualmente marginales del impuesto de renta de las dos décadas anteriores. Este artículo examina por qué el aumento del impuesto de renta fue tan difícil durante los gobiernos de centro izquierda anteriores, por qué esos gobiernos aprobaron reformas incrementales a pesar de las

* Profesora asistente del Departamento de Desarrollo Internacional de la London School of Economics [tasha.fairfield@gmail.com]. Traducción de Alberto Supelano. La versión original de este artículo se publicó en J. E. Mahon, M. Bergman y C. J. Arnson, eds., Progressive tax reform and equality in Latin America, Washington, D.C., Woodrow Wilson Center, Latin American Program, 2015. Se publica con las autorizaciones correspondientes. Fecha de recepción: 6 de febrero de 2015, fecha de aceptación: 19 de febrero de 2015. Sugerencia de citación: Fairfield, T. "La economía política de la reforma tributaria progresiva en Chile", Revista de Economía Institucional 17, 32, 2015, pp. 129-156. DOI: 10.18601/01245996.v17n32.04

${ }^{1}$ Algunas partes del análisis se tomaron de Fairfield (2010 y 2013). Un análisis más detallado de la reforma tributaria en Chile aparece en Fairfield (2015). La investigación de campo tuvo el apoyo del Social Science Research Council y del International Center for Tax and Development. La autora agradece a Stephen Kaplan por sus útiles comentarios en el Taller del Woodrow Wilson Center sobre Economía Política de la Reforma Tributaria en América Latina, realizado en diciembre de 2012.

${ }^{2}$ Las participaciones en la distribución del ingreso se ajustaron por el ingreso no declarado; las tasas efectivas incluyen el impuesto de renta personal y el impuesto de sociedades. Ver el análisis en Fairfield y Jorratt (2014). 
restricciones que enfrentaban, y por qué el nuevo contexto político posterior a la oleada de protestas estudiantiles de 2011 y 2012 creó la oportunidad para una reforma tributaria progresiva mucho más sustancial en 2014.

Grandes obstáculos políticos impidieron la reforma tributaria progresiva durante las dos décadas que siguieron al retorno de la democracia en Chile en 1990. Fuertes actores políticos -empresarios organizados y partidos políticos de derecha (Unión Democrática Independiente, UDI, y Renovación Nacional, RN)- defendieron el modelo neoliberal de bajos impuestos establecido por la dictadura del general Augusto Pinochet. Los empresarios tenían gran capacidad para influir en las decisiones de política gracias a su fuerte asociación intersectorial, la Confederación de la Producción y el Comercio (CPC), que coordinaba el cabildeo de los diversos sectores, y tenía vínculos con los partidos de derecha, en especial con la UDI. En conjunción con los senadores designados por Pinochet, la derecha tuvo en el Senado el número de escaños suficiente para vetar la legislación durante los años noventa. En la década siguiente, la coalición de la Concertación, de centro izquierda, que gobernó de 1990 a 2010, pudo remplazar a varios senadores designados por Pinochet por miembros de la coalición. No obstante, la derecha y la izquierda estuvieron casi empatadas en el Senado durante toda la década. Pero después de 2011 el movimiento estudiantil neutralizó el poder de los empresarios y de la derecha.

La primera sección del artículo describe el sistema tributario chileno e identifica los principales factores que llevaron a la baja tributación del ingreso y las ganancias altamente concentrados; la segunda sección explica el contexto institucional y el proceso de formulación de políticas tributarias después de la democratización; la tercera sección discute las estrategias que emplearon los gobiernos chilenos para implementar alzas de impuestos incrementales, y la cuarta examina casos en los que se aplicaron con diversos grados de éxito. La quinta sección pasa a los desarrollos tributarios posteriores a las protestas estudiantiles de 2011-2012, y hace un análisis preliminar de la reforma de Bachelet de 2014, que fue aprobada en la Cámara de Diputados en septiembre, después de las grandes modificaciones introducidas en el Senado un mes antes.

\section{EL SISTEMA TRIBUTARIO CHILENO}

Igual que muchos países latinoamericanos, Chile depende fuertemente de los impuestos indirectos (gráfica 1). El recaudo del impuesto al valor agregado (IVA) fue en promedio el $8,1 \%$ del PIB en el periodo 
1993-2005, un 51\% del recaudo total; mientras que el impuesto de renta representó en promedio un 4,0\% del PIB. Aunque el recaudo total de Chile es bajo para los estándares latinoamericanos, los gobiernos chilenos han enfrentado periódicas necesidades de ingreso fiscal (salvo en el periodo 2006-2009, cuando el aumento exógeno del precio del cobre produjo un ingreso fiscal más alto). Debido a que la base del IVA ya es muy amplia y a que la tasa es relativamente alta (18\% de 1990 a 2003, y 19\% en adelante), el aumento del impuesto de renta pagado por los individuos de ingresos más altos y las grandes empresas ha sido una opción obvia para elevar el ingreso fiscal.

\section{Gráfica 1}

Ingreso tributario en Chile, 1993-2005

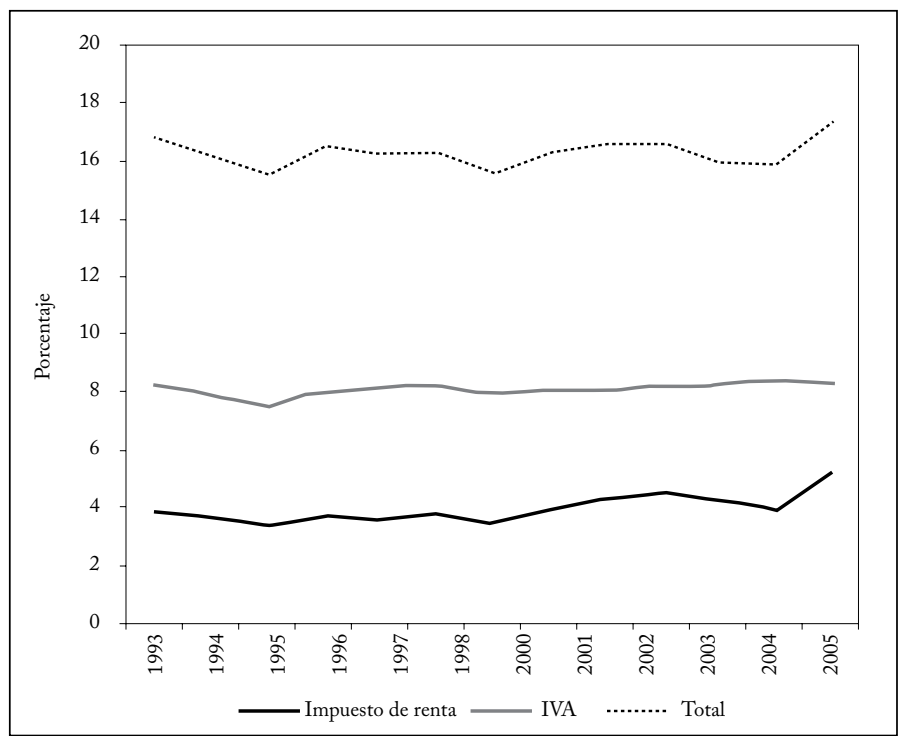

Fuente: Serie de Ingresos Tributarios [www.sii.cl].

Es imperativo entender las características únicas del sistema tributario chileno para entender la baja tributación del ingreso y las ganancias, y los parámetros del problema de la reforma tributaria. Chile tiene un sistema de impuesto de renta integrado que vincula el impuesto de sociedades y el impuesto personal. Las empresas pagan un impuesto de sociedades sobre sus utilidades. Este impuesto de sociedades funciona como una retención con respecto a los impuestos personales de sus propietarios. Cuando una empresa reparte utilidades a los propietarios, estas utilidades entran en la base gravable de los propietarios, pero estos reciben un descuento por el impuesto de sociedades correspon- 
diente que ya pagó la compañía. Este mecanismo asegura que la renta del capital no esté sujeta a doble tributación.

Las tasas del impuesto de renta personal para los chilenos ricos son mucho mayores que la tasa del impuesto de sociedades. En 2013, la tasa marginal máxima del impuesto de renta era del $40 \%$, mientras que la tasa del impuesto de sociedades era de apenas el 20\%, una de las más bajas de América Latina. Se buscaba que esta enorme brecha en las tasas de impuestos creara incentivos para que las empresas reinvirtieran sus ganancias y, con ello, contribuyeran al crecimiento económico y al desarrollo. Pero el sistema del impuesto de renta tuvo una consecuencia problemática y no intencionada: facilitó la elusión y la evasión del impuesto. Los propietarios de empresas organizadas como sociedades, que son mucho más comunes que las compañías que cotizan en bolsa, encontraron numerosas maneras de consumir las ganancias sin declararlas como ingreso individual (que estaría sujeto a tasas de impuesto de renta personal mucho mayores). Por ejemplo, un vehículo recreativo de uso personal se podía registrar a nombre de la firma y no del propietario, o el propietario simplemente podía omitir las utilidades repartidas en su declaración de impuestos personal. Era muy difícil que el servicio de impuestos controlara la evasión del impuesto de renta por falta de acceso adecuado a la información que permitiera detectar las utilidades repartidas no declaradas. Además, los profesionales independientes creaban regularmente "compañías de inversión" para transformar ingresos que estarían sujetos a las altas del impuesto de renta personal en ingresos de sociedades sujetos a una tasa de impuesto mucho menor. Los asalariados eran los únicos contribuyentes que no podían manipular el sistema del impuesto de renta en su provecho; su impuesto de renta es retenido automáticamente por los empleadores.

En últimas, la enorme brecha entre las tasas del impuesto de renta personal y de sociedades poco estimuló la inversión productiva, y fue una fuente de elevados gastos fiscales (Jorratt, 2009). E1 servicio de impuestos calcula que la evasión del impuesto a las ganancias de las empresas costó al Estado el 0,9\% del PIB en recaudo tributario potencial en 2003 (SII, 2004). Debido a que la renta del capital está altamente concentrada, este trato especial de la renta del capital también erosiona la progresividad del impuesto de renta.

Los numerosos tratamientos especiales y privilegios adicionales de la renta del capital, incluidas las bajas tasas de impuestos y las exenciones a las ganancias del capital, erosionaron aún más la capacidad de recaudo y la progresividad del impuesto de renta. El gasto total en 
impuesto de renta (es decir, el ingreso que se podría haber recaudado) fluctuó entre el 3,1\% y el 4,4\% del PIB de 2003 a 2008 (Jorratt, 2012).

Esta discusión muestra que el incremento de la tasa del impuesto de sociedades y la supresión de los privilegios tributarios a la renta del capital es esencial para aumentar la capacidad de recaudo y la progresividad del impuesto de renta en Chile. Los casos que se examinan más adelante, así como el proyecto de reforma mucho más radical de Bachelet, son ejemplos de tales medidas.

\section{EL PROCESO POLÍTICO DE LA REFORMA TRIBUTARIA}

E1 estable entorno institucional chileno, junto con su sistema de partidos relativamente estable y el sector empresarial muy organizado y cohesionado, contribuyeron a un esquema consistente de formulación de políticas tributarias desde 1990 hasta 2010, durante los gobiernos sucesivos de la Concertación. La Constitución chilena otorga al poder ejecutivo la iniciativa exclusiva en materia de política tributaria. Las autoridades de la rama ejecutiva en el Ministerio de Hacienda redactaban las iniciativas de reforma, consultando a menudo a legisladores y líderes de asociaciones empresariales para evaluar la factibilidad política de los cambios de política tributaria propuestos. Cuando el poder ejecutivo percibía que una opción de reforma no tendría suficiente apoyo en el Congreso o que provocaría una fuerte oposición de las organizaciones empresariales, descartaba esa opción. La previsión de un veto de la derecha y de los senadores designados por Pinochet en el Congreso llevó a retirar de la agenda numerosas iniciativas de reforma del impuesto de renta en los años noventa. Después de la transición a la democracia los gobiernos también tuvieron incentivos para no provocar conflictos sobre tributación con los empresarios, una preocupación básica del sector privado que apoyó a Pinochet. El esquema informalmente institucionalizado de consulta con las asociaciones empresariales sobre todos los asuntos de política económica reforzó los incentivos para evitar el conflicto con los empresarios en áreas que afectaban sus intereses básicos (Silva, 1997), con el fin de no perturbar la cooperación productiva en otros asuntos (Fairfield, 2010).

Si la rama ejecutiva percibía que había posibilidades reales de que se aprobara una iniciativa de reforma tributaria, enviaba un proyecto de ley al Congreso. La reforma se discutía primero en la cámara baja y después en el Senado. Como el centro derecha tenía mayor representación en el Senado que en la cámara baja, debido en parte a que las reglas electorales se suelen interpretar en favor de la derecha, las 
modificaciones más significativas de los proyectos de reforma tendían a surgir en negociaciones en la cámara alta. Aunque los legisladores solo pueden votar para aceptar o rechazar medidas de un proyecto de reforma tributaria -no pueden modificar el texto del proyecto debido a la iniciativa exclusiva del ejecutivo-, este solía negociar modificaciones para aplacar a la derecha (y a veces para mantener la disciplina dentro de la coalición de gobierno). Las modificaciones a menudo eran necesarias para asegurar los votos suficientes para aprobar la legislación. Además, los gobiernos de la Concertación tendían a preferir asegurar al menos algunos votos de la oposición con el fin de reforzar la legitimidad y la longevidad de las reformas; este estilo de formulación de políticas surgió de la experiencia de notables líderes de la Concertación durante el golpe de 1973 y la dictadura. Por razones similares, los gobiernos tendían a subutilizar las enormes facultades constitucionales del ejecutivo (Siavelis, 2002). Además, el uso de la facultad de veto era una "opción nuclear" que en el futuro podría perjudicar la capacidad del ejecutivo para negociar reformas con la oposición ${ }^{3}$.

\section{EL REPERTORIO DE ESTRATEGIAS DE LA CONCERTACIÓN}

La Concertación desarrolló un repertorio de lo que llamo "estrategias del lado tributario" y "estrategias del lado de los beneficios" para manejar la fuerte oposición de la comunidad empresarial y de la derecha ${ }^{4}$. Las primeras, que incluyen la atenuación del impacto y los llamados a la legitimidad, aplican técnicas basadas en el diseño o de encuadre. Las segundas -que incluyen el énfasis en la disciplina fiscal, la compensación y la vinculación al gasto social- centran la atención en los beneficios que se financiarán con os impuestos. Estas estrategias son diseñadas para movilizar el apoyo popular y/o para mitigar la resistencia de la élite a la reforma. Algunas de ellas también han servido para consolidar el apoyo de la coalición de gobierno; las divisiones entre su ala más orientada al mercado y su ala de izquierda más estatista amenazaron a veces la disciplina en materia tributaria. En esta sección reviso cada estrategia y explico los factores en que se basa su éxito potencial y los que han limitado a veces su efectividad. Algunas estrategias se han vuelto menos efectivas (si no usadas con

\footnotetext{
${ }^{3}$ Entrevista de la autora con Patricio Navia, Santiago, 25 de junio de 2012. Sobre los incentivos para la cooperación creados por el sistema de partidos de Chile, ver Flores (2010).

${ }_{4}$ Para un tratamiento teórico más general de estas estrategias de reforma tributaria, con aplicaciones a casos de países latinoamericanos adicionales, ver Fairfield (2013).
} 
menos frecuencia) con el tiempo, mientras que otras se han vuelto cada vez más potentes debido al carácter cambiante de la competencia electoral. En general, la Concertación ha usado diversas estrategias de reforma cuando propone un alza de impuestos particular.

\section{ATENUACIÓn DEL IMPACTO}

Esta estrategia recurre al gradualismo para minimizar la oposición a la reforma limitando su impacto. En vez de intentar una reforma integral, los gobiernos de la Concertación buscaron reformas incrementales, el aumento gradual de las tasas de impuestos y la ampliación de la base gravable cuando era factible, de acuerdo con la expresión del presidente Patricio Aylwin (1990-1994) de que la reforma se debía emprender "en la medida de lo posible"5.

Los gobiernos de la Concertación usaron dos técnicas de diseño de reformas para atenuar el impacto: reformas "por etapas"y “temporales". Las reformas por etapas implican una implementación gradual. Por ejemplo, un aumento de la tasa de impuestos se puede implementar mediante incrementos pequeños durante un intervalo de varios años, o se puede establecer que una medida de ampliación de la base tenga efecto varios años después de su aprobación en el Congreso. La reforma por etapas da a la comunidad empresarial un periodo de transición para ajustar los planes de inversión o terminar proyectos que estén en ejecución antes del cambio de las normas tributarias. Así, ayuda a reducir la oposición empresarial y puede neutralizar las preocupaciones por el impacto potencial del aumento de impuestos sobre la inversión.

La segunda técnica consiste en legislar un aumento de impuestos por un periodo de tiempo limitado, después del cual recuperará vigencia la legislación anterior a la reforma. $\mathrm{El}$ presidente Eduardo Frei Montalva (1964-1970) usó variantes de esta técnica en los años sesenta (Ascher, 1984,131). También se usó en la conocida reforma tributaria chilena de 1990; el diseño inicial del aumento del impuesto de sociedades como un impuesto temporal ayudó a atraer a los empresarios y a la derecha, y la Concertación después logró hacerlo permanente. De hecho, cada vez que un gobierno legislaba un alza de impuestos temporal, la reforma después la renovaba o la hacía permanente. La renegociación de reformas que ya han estado vigentes varios años suele ser más fácil que la aprobación de reformas por vez primera; los gobiernos podían argumentar convincentemente que el

5 Aylwin usó esta frase refiriéndose a su búsqueda circunscrita de justicia para oficiales del ejército después de la transición a la democracia; ver El Pais (1991). 
alza de impuestos en cuestión no perjudicaba la inversión y que una pérdida abrupta de recaudo amenazaría la disciplina fiscal (ver más adelante la discusión del énfasis en la disciplina fiscal).

Aunque las técnicas que atenúan el impacto ayudaron a la Concertación a legislar aumentos tributarios, con el tiempo los empresarios y la derecha tomaron conciencia de esta estrategia y tendieron a oponerse incluso a alzas de impuestos incrementales. Un ex gerente general de la CPC explicó así la posición de los empresarios: "Lo que sucedió con muchos gobiernos de la Concertación es que si se analiza una ley o parte de una ley dada no tiene gran impacto en sí misma, pero si se añade una ley ahora y otra seis meses después, y otra y otra,

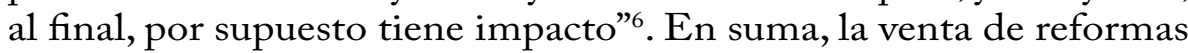
como algo "temporal" se volvió menos efectiva con el tiempo, pues los empresarios y la derecha preveían que los gobiernos intentarían hacer permanentes todas esas reformas en el futuro; en esencia, las promesas de que las alzas de impuestos serían temporales perdieron credibilidad.

\section{LLAMADOS A LA LEGITIMIDAD}

Los llamados a la legitimidad buscan movilizar el apoyo público recurriendo a normas ampliamente aceptadas como la equidad, y presionar así a los políticos para que acepten reformas a las que se podrían oponer. Los gobiernos de la Concertación emplearon esas llamados en un esfuerzo por desviar la atención de la derecha de los intereses básicos de sus votantes empresariales, y se centrara en cambio en el electorado más amplio y en los costos electorales potenciales de oponerse a los aumentos de impuestos.

Estos gobiernos emplearon dos tipos principales de llamados a la legitimidad. El primero, los llamados a la equidad vertical, recurre al principio de que los impuestos deben ser progresivos. Los llamados a la equidad funcionan mejor en conjunción con reformas progresivas que apuntan claramente a las élites económicas en vez de afectar a los sectores de ingreso medio o más bajo. Así como en otros países, en Chile los empresarios y la derecha solían decir que el alza de impuestos afectaba a las empresas pequeñas o a la clase media -por lo general, profesionales más acomodados que el ciudadano promedio pero que no pertenecen a la élite realmente rica. Este argumento es más difícil de sostener cuando el alza de impuestos afecta estricta y patentemente a los contribuyentes más ricos.

${ }^{6}$ Entrevista de la autora con un ex directivo de la asociación empresarial, Santiago, 12 de marzo de 2007. 
Los llamados a la equidad vertical también sirvieron para que los legisladores de la Concertación apoyaran las propuestas tributarias del ejecutivo. Por una parte, la focalización de las alzas de impuestos en sectores de ingresos más altos ayudó a conseguir el apoyo de los demócrata-cristianos más conservadores de la coalición de gobierno, que solían ser sensibles al argumento de que el alza de impuestos perjudicaría a la clase media; en los años 2000 el Partido Demócrata Cristiano (PDC) compitió con la UDI para representar a los sectores de “clase media" (Navarette, 2005; Huneeus, 2003, 122). La posibilidad de que los demócrata-cristianos y otros legisladores del ala conservadora de la Concertación se aliaran con los empresarios y la derecha contra las propuestas tributarias del ejecutivo fue una preocupación frecuente para los tecnócratas del Ministerio de Hacienda. Por otra parte, los llamados a la equidad vertical ayudaron a obtener el apoyo del ala izquierda de la Concertación, que se quejaba con frecuencia porque las políticas del gobierno no eran suficientemente redistributivas. Con este fin, el ejecutivo trató de usar llamados a la equidad vertical para promover incluso alzas de impuestos que, en sentido estricto, eran regresivas, como la del IVA en $2003^{7}$.

E1 segundo tipo de llamado a la legitimidad recurre al principio de equidad horizontal: los individuos o firmas que reciben ingresos similares deben pagar impuestos similares aunque sus fuentes de ingreso sean diferentes. La supresión de incentivos fiscales sectoriales y la ampliación de la base del impuesto de renta para incluir rentas del capital exentas son ejemplos de reformas que mejoran la equidad horizontal. El recorte de la evasión de impuestos también la mejora. Los llamados a la equidad horizontal no solo pueden movilizar el apoyo público sino que incluso pueden atraer apoyo empresarial. Por ejemplo, las firmas que acatan la ley tienden a apoyar reformas diseñadas para controlar la evasión del impuesto de sociedades ${ }^{8}$. En teoría, la supresión de beneficios tributarios sectoriales también puede generar apoyo de sectores empresariales que no reciben esos beneficios. En Chile, sin embargo, las reformas para eliminar beneficios tributarios de sectores específicos recibían a lo sumo una aprobación tácita del sector empresarial, dada la fuerte solidaridad de los empresarios contra las alzas de impuestos. En algunos casos, la comunidad empresarial

\footnotetext{
7 Estos llamados decían que el grueso del recaudo del IVA se origina en los grupos de ingreso más alto, dada la extrema desigualdad en Chile.

${ }_{8}$ En Chile, el apoyo empresarial a las reformas contra la evasión varió dependiendo de las medidas propuestas; p. ej., los empresarios aceptaban multas más altas a la evasión pero se oponían fuertemente a dar mayores facultades de auditoría al servicio de impuestos.
} 
se opuso en forma unánime a reformas que buscaban aumentar el recaudo de sectores que pagaban impuestos demasiado bajos.

Los llamados a la legitimidad son más efectivos cuando la competencia política es fuerte y cuando se acercan elecciones importantes. En esas condiciones los políticos tienden a estar más sintonizados con la opinión pública. Sin embargo, la investigación sobre partidos y representación política muestra que numerosos factores pueden quebrar la lógica de la responsabilidad democrática, y que los políticos pueden evitar el castigo electoral aunque sus posiciones políticas diverjan de la opinión pública9 ${ }^{9}$ En Chile, el carácter de los lazos de la UDI con su electorado atenuó el efecto de los llamados a la legitimidad. Aunque el partido atrae apoyo de las élites económicas con base en sus posiciones de política económica, incluida la baja tributación, obtiene votos de sectores de bajos ingresos mediante llamados personalistas y el clientelismo en pequeña escala (Luna, 2010). Por ello, la UDI ha tenido margen para mantener el apoyo de la masa electoral a pesar de las posiciones políticas contra la redistribución.

\section{EL ÉNFASIS EN LA DISCIPLINA FISCAL}

El énfasis en la disciplina fiscal fue una característica coherente de la política tributaria chilena de 1990 a 2010. Durante la transición a la democracia, los empresarios organizados y la derecha mostraron preocupación por que la Concertación gastara en forma irresponsable, lo que veían como una de las causas principales de los problemas económicos del gobierno del presidente Salvador Allende (1970-1973). Mostrar que un mayor recaudo fiscal era esencial para mantener la disciplina fiscal -dada la creciente demanda de recursos del gobierno en el contexto de democratización- fue esencial para aprobar la reforma tributaria de 1990 y hacer permanente el aumento del impuesto de sociedades en 1993 (Boylan, 1996; Marcel, 1997; Weyland, 1997). Pero después de 2005 el énfasis en la disciplina fiscal fue una estrategia menos efectiva debido a los elevados excedentes fiscales ligados a los altos precios del cobre. Los ingresos del cobre entraban a las arcas del Estado a través de Codelco, la compañía minera de propiedad del Estado, y a través del boyante sector cuprífero privado. Incluso los políticos de la coalición de gobierno cuestionaron la necesidad de aumentar impuestos para respaldar nuevos gastos del gobierno en este contexto.

La Concertación casi siempre vinculó el énfasis en la disciplina fiscal al gasto social o a la compensación a la élite. De hecho, vincular

${ }^{9}$ Ver, p. ej., Hacker y Pierson (2005) y Hacker (2010).

Revista de Economía Institucional, vol. i7, N.o 32, Primer Semestre/20i5, PP. I 29-i56 
el alza de impuestos al gasto social requiere tácita o explícitamente argumentar que el aumento del gasto solo es aceptable si se pueden generar nuevos recursos para financiarlo. Esa misma observación es válida en el caso de formas de compensación a las élites que implican costos fiscales, como la reducción de otros impuestos.

\section{LA VINCULACIÓN AL GASTO SOCIAL}

La vinculación al gasto social es una estrategia para movilizar el apoyo público y presionar a los políticos para que acepten alzas de impuestos. Las estrategias de vinculación ayudan a que los promotores de la política culpen a los legisladores que votan contra la reforma y también pueden crear incentivos positivos para que los políticos apoyen la reforma permitiéndoles compartir el crédito por proporcionar beneficios populares.

La vinculación del alza de impuestos al gasto social tiene una larga historia en Chile. E1 presidente Frei Montalva utilizó con frecuencia esta estrategia en los años sesenta (Ascher, 1984, 129-130, n. 18). La vinculación al gasto jugó un papel clave para generar apoyo a la reforma tributaria de 1990 y se empleó en cada aumento de impuestos después de 1990, solo con dos excepciones (Boylan, 1996, n. 25) ${ }^{10}$. Los funcionarios del gobierno de Lagos y de gobiernos de la Concertación anteriores dijeron en forma consistente que los aumentos de impuestos solo eran factibles cuando el ejecutivo podía argumentar que programas particulares requerían financiación. De acuerdo con el ex presidente Ricardo Lagos, "La clave para una reforma tributaria es vincularla a la destinación de los fondos. Nunca quise discutir la reforma tributaria, discutí lo que se iba a hacer con el dinero"11. En forma similar, el ex ministro de hacienda Manuel Marfán comentó: "Se debaten las políticas públicas y la financiación en el mismo paquete. Forman partes de un todo [...] Ese es un elemento clave"12.

La Concertación usó tres técnicas para vincular los aumentos de impuestos al gasto. En algunos casos, los vínculos solo eran parte del discurso. Una segunda técnica, más sólida, era incluir formalmente nuevos programas de gasto con los aumentos de impuestos en la misma propuesta legislativa, obligando a que ambos aspectos

10 Estas excepciones fueron el aumento del impuesto de sociedades de 2001, que fue neutral al recaudo debido al recorte de la tasa del impuesto de renta que lo acompañó, y el impuesto a la minería de 2005, que tuvo fuerte apoyo público por sentimientos nacionalistas.

${ }^{11}$ Entrevista de la autora con el ex presidente chileno Ricardo Lagos, Berkeley, Ca., 20 de septiembre de 2006.

12 Entrevista de la autora con Manuel Marfán, ex subsecretario de hacienda (1994-1999) y ex ministro de hacienda (1999-2000), 25 de octubre de 2005. 
se debatieran al mismo tiempo y haciendo más claros los vínculos, como señaló Marfán en la cita anterior. Se podían crear vínculos aún más estrechos señalando que las iniciativas de gasto dependían de la aprobación del alza de impuestos. Esta tercera técnica fue posible porque la rama ejecutiva chilena tiene el privilegio de iniciativa exclusiva en reformas tributarias; como se señaló más atrás, solo el ejecutivo puede proponer o enmendar un proyecto de ley tributaria; aunque los legisladores pueden aprobar o rechazar medidas del proyecto de ley, no pueden cambiar la redacción ni el contenido de un artículo. Por ello, el ejecutivo podía redactar una propuesta de modo que si se rechazaba el alza de impuestos, el programa de gasto que se financiaría no se llevaría a cabo. Esa dependencia hace posible la vinculación más estrecha al gasto social, porque la destinación específica es inconstitucional en Chile.

La vinculación al gasto social pudo ser una estrategia efectiva para reducir la oposición de la derecha por dos razones. Primera, en Chile tendía a haber más consenso entre la izquierda y la derecha sobre el gasto social que sobre la tributación. El régimen de Pinochet inició el gasto focalizado durante la dictadura, en parte para crear una base de apoyo popular (Etchemendy, 2011), y la Concertación después adoptó y amplió ese modelo (Castiglioni, 2005). Segunda, los legisladores de derecha pueden sentir presión electoral para que apoyen programas populares ${ }^{13}$. Especialmente en los casos en que el programa social se considera $-\mathrm{O}$ se puede enmarcar fácilmente como- bien justificado con base en la equidad o la moralidad, como las pensiones de los ancianos pobres, y oponerse a un alza de impuestos asociada al gasto social puede ser políticamente perjudicial. Un diputado de la UDI comentó: "Sí, la capacidad del gobierno para decir 'no, esas personas no quieren mejorar los proyectos sociales y no darán dinero para eso' tiene impacto [...] La historia que el gobierno logra armar nos perjudica"14.

Los empresarios también eran sensibles a la posibilidad de que el rechazo de los aumentos de impuestos diseñados para financiar gasto social perjudicara su imagen pública y promoviera demandas de una mayor redistribución. Algunos empresarios entrevistados admitieron que esta estrategia hacía más difícil oponerse a los aumentos de impuestos $^{15}$. Sin embargo, los empresarios y la derecha solían replicar

${ }_{13}$ Sobre los incentivos electorales que motivan a los partidos de derecha e izquierda para ampliar los programas sociales, ver Garay (s. f.).

${ }^{14}$ Entrevista de la autora con un diputado de la UDI, Santiago, 23 de diciembre de 2005 .

${ }_{15}$ Entrevistas de la autora con un ex dirigente de la asociación empresarial, Santiago, 13 de diciembre de 2005, y con un ex directivo de la asociación empresarial, 2007 (ver la nota 6). 
que el gasto social se debía financiar con una mayor eficiencia, la reasignación, la privatización o el simple crecimiento económico.

\section{COMPENSACIÓN}

Estas estrategias proporcionan beneficios a las élites que soportan la carga del alza de impuestos. La compensación puede tomar muchas formas, desde la adopción de políticas que los empresarios defienden hasta la reducción de impuestos distintos de aquellos que se propone aumentar. Los gobiernos de la Concertación a menudo crearon incentivos a la inversión alternativos para que remplazaran a los beneficios tributarios que proponían eliminar o, simultáneamente, redujeron impuestos ineficientes a los que se oponían los empresarios. Los gobiernos a veces compensaron a los empresarios con acuerdos de estabilidad tributaria. En 1993, el gobierno de Aylwin pudo hacer permanente el aumento del impuesto de sociedades de 1990 a cambio de reducir las tasas superiores del impuesto de renta personal, y acordó de manera informal no elevar los impuestos directos durante los cuatro años siguientes. El gobierno de Lagos ofreció beneficios a las compañías mineras en forma de cláusulas extendidas de invariabilidad tributaria para atenuar la oposición al impuesto a la minería de $2005^{16}$.

Dada la fortaleza de los empresarios y de la derecha, usualmente fueron necesarias formas significativas de compensación para reducir la oposición al aumento de los impuestos progresivos en Chile. En cambio, los gobiernos argentinos pudieron legislar alzas de impuestos más sustanciales a cambio de formas de compensación menos costosas, dada la debilidad y la fragmentación organizativa del sector empresarial argentino y la ausencia de un partido con fuertes lazos con las élites económicas en el Congreso (Fairfield, 2015).

\section{ESTUDIOS DE CASO}

Esta sección analiza tres estudios de caso del gobierno del presidente Ricardo Lagos (2001-2005): la reforma contra la evasión de 2001, el aumento del impuesto de sociedades de 2001 y la supresión del artículo 57 bis en 2005 , un crédito tributario para ciertos propietarios de acciones. Estas reformas fueron las iniciativas más importantes para aumentar el recaudo del impuesto de renta y la equidad después de la reforma tributaria de 1990, que elevó la tasa del impuesto de

\footnotetext{
${ }^{16}$ Se usó una técnica similar cuando el gobierno de Piñera aumentó el impuesto a la minería para ayudar a financiar la reconstrucción después del fuerte terremoto de 2010 .
} 
sociedades del 10\% al 15\%. Los llamados a la equidad minimizaron efectivamente la oposición de la derecha a la reforma de 2005, dada la gran importancia de la desigualdad en la campaña presidencial. En cambio, algunas estrategias fueron marginalmente efectivas en las reformas de 2001. Esta sección termina con un breve análisis de la evolución del impuesto de renta durante el primer año del gobierno de centro derecha de Piñera (2010-2013).

\section{LA REFORMA CONTRA LA EVASIÓN}

Los llamados a la equidad y el diseño estratégico de la reforma ayudaron al gobierno de Lagos a legislar la reforma contra la evasión de 2001, durante un periodo de recesión económica y fuerte oposición de los empresarios y de la derecha. Por conveniencia política, el gobierno intentó elevar el recaudo principalmente con medidas para combatir la evasión de impuestos indirectos. Pero el Ministerio de Hacienda también propuso limitar algunos beneficios del impuesto de renta que facilitaban la evasión. Estas medidas para ampliar la base del impuesto de renta poco elevaron el recaudo pero fueron muy controvertidas. Aunque los llamados a la equidad no evitaron la confrontación con los empresarios y la derecha, estas estrategias fueron no obstante esenciales para legislar la reforma.

El gobierno usó llamados a la equidad vertical y horizontal en un esfuerzo por minimizar la oposición de los empresarios y la derecha. Por ejemplo, el presidente Lagos invocó la equidad vertical en una manifestación pública en septiembre de 2000 , en la que anunció que no era justo que los chilenos de escasos recursos pagaran el $18 \%$ del IVA en sus compras mientras que los de mayores recursos usaban los vacíos legales para evitar pagar sus impuestos de renta. Añadió: "Hay malos chilenos que no pagan todos sus impuestos. Por esa razón, envié una propuesta a la legislatura encaminada a terminar la evasión de impuestos, para que todos paguen su justa contribución al progreso de Chile" (El Mercurio, 2000). Entretanto, el texto de la propuesta llamó así a la equidad horizontal: "La evasión de impuestos representa una situación de gran desigualdad, entre quienes cumplen sus obligaciones tributarias y quienes no las cumplen. Corregir esta desigualdad no es solo un imperativo ético, es también indispensable para el adecuado funcionamiento de una economía moderna [...] El hecho de que algunas compañías cumplan sus obligaciones tributarias crea una situación de competencia desleal frente al resto del sector privado" 17 . El gobierno también aplicó llamados a la equidad a las

17 Mensaje de Proyecto 178-342, 10 de julio de 2001. 
medidas para ampliar la base del impuesto de renta, calificando como evasión de impuestos al uso de lo que los empresarios y la derecha consideraban beneficios tributarios legales. Describió estas medidas tributarias como una manera de refrenar el comportamiento moralmente inapropiado, y no solo como un medio alternativo para elevar el recaudo, para desacreditar y debilitar la oposición empresarial. La reforma contra la evasión también fue vinculada vagamente al gasto social, pero esta estrategia jugó un papel secundario, dada la fuerte legitimidad de la reducción de la evasión ${ }^{18}$.

Aunque el gobierno tuvo que negociar concesiones importantes, los llamados a la equidad ayudaron a tramitar el paquete en el Congreso. Entrevistados del gobierno afirmaron que la estrategia ejerció fuerte presión sobre la derecha. El ex presidente del Senado dijo que la derecha estaba en una posición incómoda: "Definitivamente creo que se convencieron de que su argumento no estaba bien fundado. [Entrevistador: ¿De modo que en su opinión, la derecha estaba en una posición defensiva?] Así es. Totalmente defensiva. Se opuso a todo lo que mostrara incluso el más leve indicio de un gravamen o tasa de impuestos más altos. Buscó todo tipo de argumentos" ${ }^{19}$. En forma similar, un eminente senador de la Concertación afirmó: "Para la oposición, nunca fue fácil oponerse firmemente a las reducciones de la evasión de impuestos. Tenían una legitimidad básica, y eran una parte muy importante del paquete. [Entrevistador: Pero la derecha argumentó que era una reforma tributaria disfrazada, ¿eso fue eficaz?] No, y finalmente tuvo que aceptar que era razonable" ${ }^{20}$. De hecho, dos senadores de derecha explicaron a la prensa que se habían abstenido en vez de votar contra la reforma durante las sesiones del Comité de Finanzas en previsión de las recriminaciones perjudiciales del gobierno: "Si no hubiéramos hecho eso, el presidente Lagos habría dicho que la oposición se oponía a la lucha contra la evasión de impuestos” (El Mercurio, 2001).

\section{EL AUMENTO DEL IMPUESTO DE SOCIEDADES DE 2001}

El aumento del impuesto de sociedades de 2001, una idea que tomó forma mientras se debatía la reforma contra la evasión, se legisló con una mezcla diferente de estrategias. Las estrategias centrales en este

${ }^{18}$ Entrevistas de la autora con Ricardo Lagos, 2006 (ver nota 11) y con Edgardo Boeninger, ex ministro de la Secretaría General de la Presidencia y senador del PDC (1998-2006), Santiago, 14 de noviembre de 2005.

${ }^{19}$ Entrevista de la autora con un senador demócrata-cristiano, Santiago, 26 de marzo de 2007.

${ }^{20}$ Entrevista de la autora con Boeninger, 2005. 
caso fueron la compensación a las élites económicas y el énfasis en la disciplina fiscal; también se emplearon llamados a la equidad y el aumento por etapas.

El moderado incremento del impuesto de sociedades del 15\% al $17 \%$ se hizo posible por la reducción simultánea de las tasas del impuesto de renta personal de los individuos de los intervalos de ingreso más altos; el proyecto de ley propuso reducir la tasa marginal máxima del $45 \%$ al $40 \%$, reducir la tasa del segundo intervalo más alto del $35 \%$ al $32 \%$ y crear un intervalo intermedio con una tasa del $37 \%$. De acuerdo con los cálculo del Ministerio de Hacienda, este recorte de impuestos (junto con las modificaciones adicionales que se describen más adelante) compensó exactamente los incrementos de recaudo provenientes del aumento del impuesto de sociedades, por lo que el paquete de reformas fue neutral al recaudo. Pero el gobierno previó que la reducción de la brecha entre las tasas del impuesto personal y de sociedades reduciría los incentivos para eludir y evadir impuestos, lo que produciría algunos aumentos de recaudo en los márgenes.

Los recortes de la tasa del impuesto de renta personal compensaron a las élites económicas por el aumento del impuesto de sociedades. Los propietarios de empresas y los profesionales independientes que no participaban en los tipos de elusión y evasión descritos en la primera sección anterior obtendrían de hecho una reducción neta del impuesto de renta, porque el impuesto de sociedades es simplemente un pago anticipado de los impuestos adeudados cuando las utilidades se reparten. Los propietarios de empresas y los profesionales independientes que eludían y evadían el impuesto de renta personal tendrían un aumento muy moderado del impuesto de renta, aunque algunas otras fuentes del ingreso que recibían serían gravadas a las tasas reducidas del impuesto de renta personal.

Aunque los recortes del impuesto de renta personal contribuyeron a reducir la brecha con el impuesto de sociedades, que para el Ministerio de Hacienda era un grave problema, una función igualmente importante fue la de reducir la oposición de los empresarios y de la derecha al aumento del impuesto de sociedades ${ }^{21}$. El ex presidente Lagos describió los recortes de impuestos como un "caramelo" para aplacar a estos actores poderosos ${ }^{22}$. Como se preveía, las asociaciones empresariales respaldaron los recortes del impuesto de renta personal como un paso en la dirección correcta (CPC, 2001). Los políticos

\footnotetext{
21 Entrevista de la autora con un ex ministro de hacienda, Santiago, 25 de marzo de 2005.

22 Entrevista de la autora con Ricardo Lagos, 2006 (ver la nota 11).
} 
de derecha condonaron igualmente estas medidas ${ }^{23}$. Entretanto, el gobierno afirmó que los recortes del impuesto de renta personal eran insostenibles sin aumentar el impuesto de sociedades, dada la importancia de mantener la disciplina fiscal y sostener los programas sociales para los chilenos pobres.

Los llamados a la equidad entraron al debate de modo diferente a como entraron en la reforma contra la evasión: el gobierno, y en especial legisladores demócrata-cristianos clave, incluido el senador Alejandro Foxley, presentaron la reducción del impuesto de renta personal como un recorte de impuestos para la "clase media". La lógica era que los asalariados, cuyos impuestos son retenidos automáticamente por los empleadores, eran los únicos contribuyentes que no podían encontrar maneras de evitar las altas tasas del impuesto de renta personal, y que en la práctica pagaban tasas efectivas mucho más altas que los contribuyentes con ingresos provenientes de las empresas. Por ello, la reforma trasladaba parte de la carga tributaria efectiva de los asalariados a los propietarios de empresas evitando el impuesto de renta personal. El efecto neto de la reforma sería entonces ligeramente progresivo, dado que las ganancias recibidas predominaban sobre los demás activos y fuentes de ingreso de los contribuyentes de los intervalos de ingreso más altos.

Por supuesto, los pocos asalariados que se beneficiarían de los recortes de impuestos difícilmente pertenecían a la categoría de "clase media" basada en la distribución objetiva del ingreso en Chile. Estos contribuyentes pertenecían de hecho al 1\% superior de los adultos (Agostini et al., 2012). Pero en comparación con los magnates empresariales mucho más ricos, estos asalariados de altos ingresos encajaban en el concepto de clase media empleado por muchos políticos demócrata-cristianos que intentan atraer a estos electores, por los políticos de la coalición de derecha y por los contribuyentes en cuestión. Algo similar ocurrió en Uruguay. Esas nociones subjetivas de clase media también han tenido implicaciones importantes para la reforma tributaria en otros países de América Latina (Rius, 2013).

El gobierno apeló al universo más amplio de contribuyentes al impuesto de renta -también interpretado como "clase media"- elevando el umbral de la base gravable e introduciendo un limitado descuento tributario al pago de hipotecas. Estas medidas también apelaron a los empresarios. La CPC respaldó la afirmación del gobierno de que

${ }^{23}$ Ver, p. ej., "Diario de sesiones del Senado de Chile”, Legislatura 244, Sesión 18. a, 7 de agosto de 2001.

Revista de Economía Institucional, vol. i7, N. ${ }^{\circ} 32$, Primer semestre/2oi5, Pp. I29-I56 
el descuento tributario a las hipotecas estimularía el crecimiento del sector de la construcción (CPC, 2001).

Además de compensar a las élites y enmarcar la reforma como una mejora de la equidad vertical reduciendo la carga de la clase media, el gobierno introdujo gradualmente el controvertido aumento del impuesto de sociedades. El aumento de dos puntos se dividió en tres incrementos anuales; así, la tasa del impuesto de sociedades solo llegaría al 17\% en 2004.

La negociación de la reforma con la comunidad empresarial y con la derecha fue difícil, pese a las diversas estrategias utilizadas. Foxley describió el proceso como "un proceso muy complicado y con muchos conflictos", y un destacado senador del PDC dijo que este leve aumento del impuesto de sociedades fue la iniciativa tributaria que más disgustó a los empresarios y a la derecha durante el gobierno de Lagos $^{24}$. La mayoría de los senadores de $\mathrm{RN}$ y algunos de los designados votaron a favor del paquete de reformas como un todo, dada su aprobación de los recortes del impuesto de renta personal, pero la UDI se abstuvo de registrar su objeción al aumento del impuesto de sociedades. La UDI votó en bloque para eliminar el aumento del impuesto de sociedades durante la votación posterior artículo por artículo.

La posibilidad de legislar el aumento del impuesto de sociedades habría sido mucho peor si los recortes del impuesto de renta personal se hubiesen omitido en la reforma; las transcripciones del debate en el Senado sugieren que esta compensación fue esencial para conseguir el apoyo de las filas de la coalición de derecha y de los senadores designados. Los senadores de RN que votaron contra la moción de la UDI para eliminar el aumento del impuesto de sociedades, no obstante hablaron favorablemente de la baja tasa del impuesto de sociedades chileno; RN propuso su propia moción para aumentar el impuesto de sociedades al $16 \%$ y no al $17 \%{ }^{25}$. Los senadores designados que apoyaron el paquete de reformas como un todo también expresaron preocupaciones por el aumento del impuesto de sociedades.

\section{SUPRESIÓN DEL ARTÍ́CULO 57 BIS}

En 2005 el gobierno de Lagos utilizó los llamados a la equidad vertical para ayudar a aprobar otra reforma que ampliaba la base del impuesto de renta. Este descuento tributario, conocido como " 57 bis",

${ }^{24}$ Entrevistas de la autora con Alejandro Foxley, ex ministro de hacienda (1990-1994) y senador del PDC (1998-2006), Santiago, 19 de enero de 2006; y con un senador demócrata- cristiano, 2007 (ver la nota 19).

${ }^{25}$ Esta moción no se sometió a votación porque violaba la iniciativa exclusiva del ejecutivo. 
heredado de la dictadura, era en esencia un subsidio del gobierno a los propietarios de nuevas emisiones de acciones. La Concertación antes quiso eliminar este descuento, pero la oposición de los empresarios y de la derecha redujo las posibilidades de reforma.

Sin embargo, en la campaña presidencial de 2005 surgió una oportunidad para la reforma. El candidato de la UDI Lavín culpó a la Concertación por el insuficiente avance en la reducción de la pobreza y la desigualdad: "Después de 16 años de gobiernos de la Concertación, hay un millón y medio de chilenos que viven en condiciones de hacinamiento, 190.000 personas que viven con 37.000 pesos (65 dólares) al mes y otros seis millones de chilenos que viven con menos de 2.500 pesos (4,40 dólares) al día" (La Tercera, 2005). $\mathrm{E} 1$ presidente Lagos respondió con el siguiente desafío público: "E1 famoso artículo 57 bis aún está vigente y es una tremenda fuente de desigualdad [...] En vez de hablar tanto, ¿qué tal si mañana presentamos la propuesta de una nueva ley y en menos de 24 horas abolimos el artículo 57 bis?" (El Mercurio, 2005). El llamado a la equidad vertical fue muy efectivo. Lavín aceptó rápidamente el desafío, y la derecha siguió su ejemplo en el Senado. El proyecto de ley recibió aprobación casi unánime en el Congreso después de un breve debate. Mientras que la reforma contra la evasión tardó casi un año en el Congreso, la reforma de 2005 se aprobó en menos de un mes.

Debido al alto perfil del intercambio entre Lavín y Lagos y a la importancia de la desigualdad durante la campaña presidencial, el costo político previsto por la derecha de defender los intereses empresariales era mucho mayor que en 2000-2001, cuando el gobierno estaba trabajando para legislar la reforma contra la evasión. Si la derecha hubiese decidido oponerse a la reforma de 2005, habría dejado en manos del gobierno probar que la derecha impedía las reformas que mejoraban la equidad, y que Lavín no tenía autoridad sobre la coalición a menudo rebelde de la derecha. La derecha contrarrestó las iniciativas tributarias del gobierno advirtiendo sobre los efectos negativos para la clase media; pero este enfoque era imposible porque la reforma de 2005 afectaba estrictamente a las élites económicas. Los datos del servicio de impuestos mostraron que solo el $0,5 \%$ de los adultos recibió el $72 \%$ de los gastos fiscales asociados con el 57 bis. Con la cercanía de las elecciones, la derecha temía que los electores castigaran a Lavín en las urnas ${ }^{26}$.

${ }^{26}$ El Mercurio, 12 de mayo, 2005, p. 13; entrevista de la autora con un diputado de la UDI, 2005 (ver la nota 14). 


\section{El AUMENTO DEL IMPUESTO DE SOCIEDAdES DE PIÑERA DE 2010}

La política del impuesto de renta tuvo un viraje inesperado en 2010, cuando la recién elegida coalición de derecha del presidente Sebastián Piñera (2010-2014) aumentó temporalmente el impuesto de sociedades al 20\%. Esta reforma surgió a partir de una conjunción inusual de factores. Primero, un fuerte terremoto creó grandes e inesperadas necesidades de ingresos fiscales que hicieron imperativa el alza de impuestos en opinión de muchos economistas. Los conocedores coincidían en que el gobierno no habría considerado alzas de impuestos si el terremoto no hubiese ocurrido, a juzgar por la plataforma de la campaña de Piñera y las preferencias de los empresarios organizados y de la derecha. Segundo, Piñera recibió fuerte presión política para que señalara que su gobierno no sería un gobierno de y para las grandes empresas. Él era uno de los empresarios más ricos de Chile, y la Concertación montó una campaña para deslegitimar su presidencia sobre esa base. Los líderes de la coalición de derecha consideraron que Piñera pudo haber ganado las elecciones por un margen más amplio de haber hecho esfuerzos más concertados para atenuar las preocupaciones por posibles conflictos de intereses asociados con sus grandes empresas de negocios. Estos problemas agobiaron al gobierno durante los primeros meses de su mandato. Por ello, los asesores del gobierno esperaban que el aumento del impuesto de sociedades señalara la separación entre Piñera y el mundo empresarial y así recobrara la confianza del público.

Las estrategias iniciadas por la Concertación ayudaron a aprobar la reforma del gobierno de Piñera. Más importante, el aumento del impuesto de sociedades fue temporal y se eliminó gradualmente, en contraste con la práctica usual de la Concertación de introducir aumentos graduales de impuestos. La reforma dispuso que la tasa bajara del $20 \%$ al $18,5 \%$ en 2012 y que retornara al 17\% en 2013. Este diseño hizo más creíble el carácter temporal del alza del impuesto y ayudó a obtener aquiescencia de los empresarios y de los legisladores de la UDI. Además, el gobierno incluyó algunas formas de compensación, incluida una reducción del impuesto de timbre, que las asociaciones empresariales habían tratado de eliminar durante mucho tiempo, y mayores descuentos tributarios para las donaciones de caridad.

\section{LA POLÍTICA TRIBUTARIA DESPUÉS DE LA PROTESTA} ESTUDIANTIL DE 2011-2012: LA REFORMA DE BACHELET DE 2014

Pese a los grandes retos políticos para la tributación progresiva en Chile, los desarrollos posteriores crearon oportunidades para una 
reforma mucho más sustancial. Las protestas estudiantiles de 2011 y 2012 ampliaron drásticamente el alcance del debate sobre la tributación progresiva. Las demandas estudiantiles de una gran reforma educativa no solo crearon una enorme necesidad de nuevos ingresos fiscales, sino que los estudiantes también exigieron explícitamente que el gobierno financiara la reforma con impuestos progresivos. Cuando los políticos de izquierda y de derecha se esforzaron por mejorar sus bajos índices de aprobación y responder a este nuevo electorado organizado de jóvenes con gran capacidad perturbadora, empezó un importante debate sobre la estructura del sistema tributario. La ofensiva estudiantil obligó al gobierno de Piñera a aumentar permanentemente el impuesto de sociedades al 20\%, a pesar de su claro intento anterior de que el incremento de 2010 sería temporal, en un esfuerzo por atenuar la presión por una reforma más radical ${ }^{27}$. La campaña presidencial de 2013 centró más la atención en los temas de la tributación y la equidad. El hecho de que la derecha hubiera presidido un alza del impuesto de renta alentó a los políticos de izquierda para buscar una reforma más significativa, y los candidatos de la oposición presentaron varias propuestas radicales de reforma del impuesto de renta, en fuerte contraste con las reformas incrementales de años anteriores.

La iniciativa tributaria de la presidente Michele Bachelet de 2014 tomó forma en este nuevo contexto político de movilización social, de descontento por la desigualdad y de urgentes necesidades de ingreso fiscal para financiar el aumento del gasto social, todo lo cual relegó inicialmente las preocupaciones de los empresarios a un segundo plano. El nuevo gobierno propuso elevar la tasa del impuesto de sociedades al $25 \%$ y, más importante, eliminar el aplazamiento del pago del impuesto de los ingresos empresariales ordenando que todas las utilidades, bien fuese que se repartieran o se reinvirtieran, entrarían en la base del impuesto de renta personal ${ }^{28}$. Este gran cambio estructural eliminaría automáticamente los problemas de elusión y evasión de impuestos discutidos más atrás. En combinación con un conjunto de nuevas medidas contra la evasión que los gobiernos anteriores de

${ }^{27}$ Para un análisis más detallado de la reforma tributaria de Piñera, ver Fairfield (2015). Para un análisis integral de la política redistributiva durante el gobierno de Piñera (tributación y gasto social), ver Fairfield y Garay (2013).

${ }^{28}$ Este cambio eliminaría el Fondo de Utilidades Tributarias (FUT; es decir, las utilidades retenidas pendientes del pago del impuesto de renta personal), que ganó notoriedad durante la campaña presidencial. E1 proyecto de ley también redujo la tasa máxima del impuesto de renta personal del $40 \%$ al $35 \%$, porque la inclusión de las utilidades retenidas de las empresas en la base del impuesto de renta aumentaba drásticamente la base gravable de la parte más alta de la distribución del ingreso. 
la Concertación habían considerado pero que nunca se atrevieron a proponer, estos cambios elevarían significativamente los impuestos de los chilenos de la parte superior de la distribución del ingreso.

Los reveses electorales de los partidos de derecha de 2013 en el Congreso y la posición defensiva de los empresarios en el contexto de movilización de la sociedad civil, que amenazó la paz social y potencialmente incluso el futuro del modelo neoliberal, hicieron políticamente factible esta reforma de largo alcance. El apoyo a Bachelet de la coalición de centro derecha (Nueva Mayoría) aseguró una sólida mayoría de veintiún escaños en el Senado, mientras que la derecha solo obtuvo diecisiete. En este contexto, los empresarios aceptaron la meta de ingreso fiscal del 3\% del PIB y las inevitables modificaciones al impuesto de renta, aunque esperaban lograr cambios en los componentes que consideraban más problemáticos. En vista de la frecuente oposición anterior de los empresarios a la más mínima alza de impuestos, el gobierno consideró que el reconocimiento empresarial de que la meta de ingreso fiscal era legítima era un gran logro político. $\mathrm{E} 1$ gobierno de Bachelet procedió a garantizar la rápida aprobación del proyecto de ley en la cámara baja del Congreso en mayo de 2014.

No obstante, el Ministerio de Hacienda negoció un proyecto de ley en el Senado para que la reforma fuera más aceptable para los empresarios, la derecha y los miembros de la coalición de gobierno que mostraban preocupación. Más importante, el sistema de gravar las ganancias imputadas (renta atribuida) se hizo voluntario. Los contribuyentes podrían en cambio optar por un nuevo sistema de impuesto de renta parcialmente integrado con un impuesto de sociedades ligeramente mayor del $27 \%$ y un descuento reducido del $65 \%$ contra los impuestos de renta personal adeudados cuando los propietarios de empresas recibieran utilidades repartidas.

Tres factores interrelacionados contribuyeron al compromiso negociado: una intensa campaña empresarial contra la reforma, la disensión dentro de la Nueva Mayoría y la creciente preocupación por la desaceleración de la economía chilena. Los empresarios se opusieron enérgicamente al sistema de renta atribuida, argumentando que perjudicaría el crecimiento y la inversión pues generaría incentivos para que los propietarios de empresas retiraran sus ganancias en vez de reinvertirlas. Las asociaciones empresariales subrayaron estos puntos en sus presentaciones al Comité de Finanzas del Senado durante las sesiones ampliadas sobre la reforma. Los medios reiteraron estos argumentos; aunque publicaron comentarios favorables, la cobertura negativa fue mayor y más destacada en los principales periódicos. 
Muchos economistas ligados al centro izquierda expresaron preocupaciones similares acerca del sistema de renta atribuida y criticaron la reforma por no incluir nuevos incentivos a la inversión que sustituyeran el trato preferencial de las utilidades reinvertidas. Entre quienes expresaron públicamente su preocupación por el impacto de la reforma tributaria en la inversión había tres ex ministros de hacienda de la Concertación. Esta disensión dentro de la Concertación reforzó los argumentos de los empresarios contra la reforma.

En vista de estos argumentos, muchos demócrata-cristianos pasaron a oponerse al sistema de renta atribuida. A comienzos de julio, los informes de prensa sugirieron que el Ministerio de Hacienda reconocía que no podía contar con el voto demócrata-cristiano en favor de este artículo central de la reforma y que, por ello, la mayoría de Nueva Mayoría en el Senado no operaría (La Tercera, 2014). En este contexto, el ministro de hacienda optó por reescribir la reforma en negociación directa con los miembros del Comité de Finanzas del Senado, que incluía representantes de RN y la UDI.

La desaceleración de la economía chilena también parece haber contribuido a la decisión del gobierno de llegar a un compromiso sobre la propuesta de renta atribuida. Aunque el gobierno proyectó inicialmente un crecimiento del 4,9\% en 2014, a mediados de junio el Banco Central publicó informes que proyectaban un crecimiento de apenas el 3\% (El Mercurio, 2014). Durante la primera etapa del debate en el Senado, el ministro de hacienda se esforzó por disipar las preocupaciones sobre el impacto de la reforma tributaria en la inversión. El ministro Alberto Arenas presentó pruebas de que la inversión en activos fijos no es sensible a cambios en las utilidades reinvertidas de las empresas (Arenas, 2014a, 40-42) ${ }^{29}$. Pero a mediados de julio su discurso pasó de afirmar firmemente que la reforma tributaria no tendría un efecto relevante sobre el crecimiento y la inversión a reconocer que el debate en curso sobre la reforma contribuía a un clima de incertidumbre para la inversión (Arenas, 2014b). Los informes de prensa anunciaron que la preocupación por el crecimiento y la inversión había motivado a Bachelet a ordenar un acuerdo ampliamente negociado (La Tercera, 2014).

A la decisión del gobierno de llegar a un compromiso también puede haber contribuido un factor adicional: el tibio apoyo público a la reforma tributaria debido a su complejidad técnica y a la campaña

${ }^{29}$ De hecho, nueva investigación innovadora sobre el recorte de impuestos a los dividendos en Estados Unidos de 2003 sugiere que incluso cambios muy grandes en la tributación de la renta del capital tienen poco efecto en el comportamiento económico de las empresas; ver Yagan (2014). 
de la oposición, según la cual la reforma perjudicaría a los empresarios pequeños y a la clase media. El gobierno emprendió intensas campañas de comunicación, incluidas las reuniones en las alcaldías donde el mismo ministro de hacienda respondía preguntas de los asistentes. Los llamados a la equidad vertical se destacaron en los esfuerzos del gobierno por defender la reforma; los funcionarios reiteraron que solo afectaría a "los más acomodados" ${ }^{30}$. Pero la oposición insistió en que la reforma tendría un impacto mucho más amplio, y esas afirmaciones tuvieron un impacto significativo en la opinión pública. Las ampliamente difundidas encuestas de opinión Cadem indicaban que el apoyo a la reforma tributaria descendió del 52\% en abril al 33\% a finales de junio, mientras que la oposición aumentó de apenas un $24 \%$ al 42\% (Cadem, 2014b); a comienzos de junio, el 68\% creía que la reforma tributaria perjudicaría a la clase media (Cadem, 2014b) ${ }^{31}$.

Aunque el gobierno reescribió gran parte del proyecto de ley durante el proceso de negociación, la reforma de 2014 parece ser un paso importante para elevar la tributación de las élites económicas, sobre todo en comparación con iniciativas anteriores de los quince años posteriores a la transición democrática. El impuesto de sociedades aumentará en 7 puntos porcentuales con el nuevo impuesto de renta parcialmente integrado, mientras que los gobiernos anteriores solo se atrevieron a incrementos de 2 o 3 puntos porcentuales, y los individuos pagarán más impuestos sobre las utilidades repartidas dado el reducido descuento del impuesto de sociedades. Según cálculos del gobierno, la meta de ingreso fiscal del 3\% del PIB se mantiene intacta, y la mayor parte del recaudo todavía provendrá de los propietarios de capital situados en la parte más alta de la distribución del ingreso. Pero se debe tener cuidado para evitar que puedan surgir nuevas oportunidades de elusión y evasión de impuestos debido a la complejidad de administrar dos sistemas tributarios paralelos, así como la introducción de nuevos beneficios tributarios para las empresas pequeñas y medianas que pueden ser usados abusivamente por las grandes empresas ${ }^{32}$.

${ }^{30}$ Los funcionarios del Ministerio de Hacienda solían decir que la reforma solo afectaría al 10\%, aunque también señalaban que los cambios del impuesto de renta afectarían principalmente al 1\% más alto; ver Diario Financiero (2014).

${ }^{31}$ E1 grupo de expertos más reputado informó el 9 de junio de 2014 que solo el $29 \%$ de los chilenos pensaba que la reforma tributaria empeoraría su situación económica, pero esa cifra es aún muy alta en vista de que la reforma se centró en las élites económicas; ver CEP (2014).

${ }^{32}$ Para una crítica detallada de estos y otros problemas potenciales de la reforma, ver Agostini (2014a y 2014b). 


\section{CONCLUSIÓN}

La Concertación enfrentó grandes obstáculos para reformar el impuesto de renta progresivo entre 1990 y 2010, dada la fortaleza de los empresarios y de la derecha; estos poderosos actores organizados trataron de mantener bajos impuestos de renta. Pero el uso adecuado de diversas estrategias de reforma permitió que los gobiernos hicieran algún avance en los márgenes, sobre todo limitando o suprimiendo beneficios tributarios que beneficiaban desproporcionadamente a las grandes empresas y a los contribuyentes de ingresos más altos. Estas estrategias se han empleado en otros países de América Latina y de otros lugares para elevar la tributación de las élites económicas (Fairfield,2013). Donde los empresarios organizados y los partidos de derecha son más débiles, estas estrategias por lo general han facilitado reformas más significativas.

E1 valor de emplear diversas estrategias de reforma y buscar aumentos de impuestos incrementales cuando la oposición de los actores sociales y los partidos políticos es fuerte es una lección generalizable que emerge de los casos chilenos examinados en este artículo. Las estrategias de reforma no aseguran el éxito, pero cuantas más estrategias se puedan aplicar simultáneamente mejores son las perspectivas. Consideremos el caso de México, por ejemplo, donde la vinculación al gasto social no ha sido tan efectiva como en Chile, debido en parte a la percepción de los ciudadanos de que el Estado no garantizará que reciban los beneficios prometidos, como señala Elizondo (2014). En México, las iniciativas para ampliar la base del IVA para incluir alimentos y medicamentos han fracasado hasta ahora. Sin embargo, la combinación de incrementos progresivos del impuesto de renta, centrados estrictamente en la élite, y de llamados a la equidad vertical vinculados al gasto social podría atraer mayor apoyo público, o al menos su aceptación; en el peor de los casos, los ciudadanos comunes no estarían peor que en la actualidad. El obstáculo obvio es, por supuesto, que los grupos de ingresos más altos se pueden oponer enérgicamente a medidas que buscan gravar directamente su ingreso y su riqueza.

Entre tanto, la reforma chilena de 2014 da algunos motivos de optimismo para quienes están interesados en promover la tributación progresiva en América Latina. Las élites económicas no siempre tienen el poder político y económico suficiente para bloquear reformas a las que se oponen, aunque puedan limitar los cambios estructurales radicales. A este respecto, la presión de los movimientos sociales organizados puede ser esencial para abrir espacio político a la reforma; los "tecno-políticos" astutos pueden aprovechar tales oportunidades. 


\section{REFERENCIAS BIBLIOGRÁFICAS}

1. Agostini, C. "E1 acuerdo tributario abre espacios de elusión mayores a los que había”, Mostrador, 10 de julio, 2014a.

2. Agostini, C. "La escandalosa amnistía tributaria para evasores de altos ingresos", Diario Financiero, 9 de septiembre, 2014b.

3. Agostini, C.; C. Martínez y B. Flores. "Distributional effects of eliminating the differential tax treatment of business and personal income in Chile", Cepal Review 108, 2012, pp. 175-201.

4. Arenas, A. "La reforma tributaria que Chile necesita", presentación en el Comité de Finanzas del Senado, Santiago, 2 de junio, 2014a, 40-42.

5. Arenas A. "Dentro de los ruidos que han afectado las expectativas, también está el debate de la reforma tributaria”, La Tercera, 13 de julio, 2014b.

6. Ascher, W. Scheming for the poor: The politics of redistribution in Latin America, Cambridge, Mass., Harvard University Press, 1984.

7. Boylan, D. "Taxation and transition: The politics of the 1990 Chilean tax reform”, Latin American Research Review 31, 1, 1996, pp. 7-31.

8. Cadem. "Seguimiento semanal de opinión pública”, Estudio 21, Santiago, 9 de junio de 2014a.

9. Cadem. “Seguimiento semanal de opinión pública”, Estudio 30, Santiago, 8 de agosto de 2014b.

10. Castiglioni, R. The politics of social policy change in Chile and Uruguay: Retrenchment versus maintenance, 1973-1998, Nueva York, Routledge, 2005.

11. CEP. “Estudio nacional de opinión pública No. 71”, Santiago, Centro de Estudios Públicos, julio de 2014.

12. ÇCPC. "Observaciones de la CPC al proyecto de ley de rebaja de impuestos personales y compensaciones", Santiago, 2001.

13. Diario Financiero. "Ejecutivo responde a empresarios y lanza video para defender la reforma tributaria”, 29 de abril de 2014.

14. El Mercurio. "Lagos pidió apoyo al proyecto contra la evasión", 10 de septiembre de 2000.

15. El Mercurio. "Avance trámite de evasión tributaria", Senadores Prat y Matthei, 15 de marzo de 2001.

16. El Mercurio. "Lagos reta a Alianza a derogar exención tributaria en 24 horas", 10 de mayo de 2005.

17. El Mercurio. "Desaceleración de la economía reduciría en US $\$ 2.370$ millones los ingresos fiscales en 2014", 23 de junio de 2014.

18. El País. "Aylwin reitera que investigará a fondo la violación de los derechos humanos en Chile", 2 de enero de 1991.

19. Elizondo, C. "Progresividad y eficacia del gasto público en México: precondición para una política recaudatoria efectiva”, Latin American Program, Woodrow Wilson International Center for Scholars, 2014, [http://www.wilsoncenter.org/publication/PoliticaFiscalMexico].

20. Etchemendy, S. Models of economic liberalization, Nueva York, Cambridge University Press, 2011.

21. Fairfield, T. "Business power and tax reform: Taxing income and profits in Chile and Argentina", Latin American Politics and Society 52, 2, 2010, pp. 37-71. 
22. Fairfield, T. "Going where the money is: Strategies for taxing economic elites in unequal democracies", World Development 47, 2013, pp. 42-57.

23. Fairfield, T. Private wealth and public revenue in Latin America: Business power and tax politics, Nueva York, Cambridge University Press, 2015.

24. Fairfield, T. y M. Jorratt. “Top income shares, business profits, and effective tax rates in contemporary Chile: New evidence from tax return data”, ICTD working paper 17, Brighton, Instituto de Estudios del Desarrollo, Universidad de Sussex, 2014; versión actualizada en [http://eprints.1se.ac.uk/56016/].

25. Fairfield, T. y C. Garay. "The politics of redistribution in unequal democracies: Unexpected reforms under the right in Chile”, trabajo presentado en la reunión anual de la American Political Science Association, Chicago, 29 de agosto-1 de septiembre de 2013.

26. Flores, G. 'Statist vs. pro-market: Explaining leftist governments' economic policies in Latin America", Comparative Politics 42, 4, 2010, pp. 413-433.

27. Garay, C. "Including outsiders: Social policy expansion in Latin America”, manuscrito inédito, s. f.

28. Hacker, J. S. "Winner-take-all-politics: Public policy, political organization, and the precipitous rise of top incomes in the United States", Politics and Society 38, 2, 2010, pp. 152-204.

29. Hacker, J. S. y P. Pierson. "Abandoning the middle: The Bush tax cuts and the limits of democratic control", Perspectives on Politics 3, marzo de 2005, pp. 33-53.

30. Huneeus, C. "A highly institutionalized party: Christian Democracy in Chile", S. Mainwaring y T. Scully, eds., Christian Democracy in Latin America, Stanford, Cal., Stanford University Press, 2003.

31. Jorratt, M. La tributación directa en Chile, Serie Macroeconomía del Desarrollo 92, Santiago, Cepal, 2009.

32. Jorratt, M. "Gastos tributarios y evasión tributaria en Chile”, documento de trabajo, Centro de Estudios Públicos, Santiago, 2012.

33. La Tercera. "Iglesia pide que los votantes se informen", 27 de marzo de 2005.

34. La Tercera. "E1 debut de la estrategia del segundo tiempo", 13 de julio de 2014.

35. Luna, J. P. "Segmented party voter linkages in Latin America: The case of the UDI", Journal of Latin American Studies 42, 2, 2010, pp. 325-356.

36. Marcel, M. "Políticas públicas en democracia: el caso de la reforma tributaria de 1990 en Chile", Estudios Cieplan 45, junio de 1997, pp. 33-84.

37. Navarette, B. "Un centro excéntrico: cambio y continuidad en la Democracia Cristiana, 1957-2005”, Politica: Revista de Ciencia Politica 45, primavera de 2005, pp. 109-146.

38. Rius, A. “The Uruguayan tax reform of 2006: Why didn't it fail?", Wilson Center Latin American Program, [http://www.wilsoncenter. org/publication/Uruguay_Taxation_2013].

39. Servicio de Impuestos Internos, "Informe de gasto tributario", Santiago, SII, 2004. 
40. Siavelis, P. "Exaggerated presidentialism and moderate presidents", S. Morgenstern y B. Nacif, eds., Legislative politics in Latin America, Nueva York, Cambridge University Press, 2002.

41. Silva, E. "Business elites, the State, and economic change in Chile", S. Maxfield y B. Ross Schneider, eds., Business and the State in developing countries, Ithaca, N.Y., Cornell University Press, 1997.

42. Yagan, D. "Capital tax reform and the real economy: The effects of the 2003 dividend tax cut", working paper, 2014, [http://eml.berkeley. edu/ yagan/DividendTax.pdf].

43. Weyland, K. "Growth with equity in Chile’s new democracy?", Latin American Research Review 32, 1, 1997, pp. 37-67. 